\title{
Case of a hamartoma or hamartoma of a case?
}

\author{
Dipan J. Shah, MD, ${ }^{\mathrm{a}}$ and Michael J. Reardon, $\mathrm{MD}^{\mathrm{b}}$
}

\author{
From the Departments of ${ }^{\mathrm{a} C a r d i o l o g y}$ and ${ }^{\mathrm{b}}$ Cardiovascular Surgery, Houston Methodist DeBakey Heart \& \\ Vascular Center, Houston, Tex. \\ Disclosures: Authors have nothing to disclose with regard to commercial support. \\ Received for publication Sept 13, 2017; accepted for publication Sept 16, 2017; available ahead of print Oct 24, \\ 2017. \\ Address for reprints: Michael J. Reardon, MD, Houston Methodist DeBakey Heart \& Vascular Center, 6550 \\ Fannin, Suite 1401, Houston, TX 77030 (E-mail: mreardon@ houstonmethodist.org). \\ J Thorac Cardiovasc Surg 2018;155:351-2 \\ $0022-5223 / \$ 36.00$ \\ Copyright (C) 2017 by The American Association for Thoracic Surgery \\ https://doi.org/10.1016/j.jtcvs.2017.09.086
}

The presence of an intracardiac mass is always a cause for concern. This concern is heightened when the mass is on the left side of the heart because of the risk of systemic embolization. When a left-sided mass is accompanied by symptoms, the need for an expeditious diagnosis and a treatment plan is high. When presented with a cardiac mass, the clinician must begin a decision process. Is this a tumor or a nontissue mass such as a thrombus? If this is a tissue mass, is it benign or malignant? If malignant, is it a primary cardiac malignancy or a secondary, metastatic tumor? With each of these branch points comes a different level of risk for the patient and treatment options for the physician to consider.

In this issue of the Journal, Liu and colleagues ${ }^{1}$ present an interesting case of a left ventricular outflow tract tumor causing obstruction and symptoms. We fully agree with the decision to surgically remove the tumor. The real question being, what is the best surgical approach? The options for removal would be transaortic valve, transmitral valve, or via a left ventriculotomy. We have found a transaortic valve approach works well for benign tumors but is limiting for an adequate resection of malignant tumors. ${ }^{2,3}$ For malignant intracavitary left ventricular tumors, we have used a transmitral valve resection with the heart ex vivo using a cardiac autotransplant approach and a left ventriculotomy. ${ }^{2}$ In our cardiac tumor program, we have been referred a number of primary cardiac sarcomas that were initially diagnosed as potentially benign tumors, which led to inadequate resections and the subsequent need for a later repeat resection after tumor recurrence. ${ }^{4}$ Liu and colleagues chose to approach this using a transaortic route. Although the article does not specifically discuss their diagnostic impression, we would assume that they considered this likely a benign tumor. The surgery was a success that grew not just from good surgeons but started with a good plan.

Imaging is our frontline approach to cardiac masses. Cardiac magnetic resonance imaging is particularly helpful in identifying perfusion to the mass that suggests tissue and not thrombus. If there is perfusion and it appears to be a primary cardiac tumor, these are unusual, with approximately three quarters being benign and one quarter tumors.

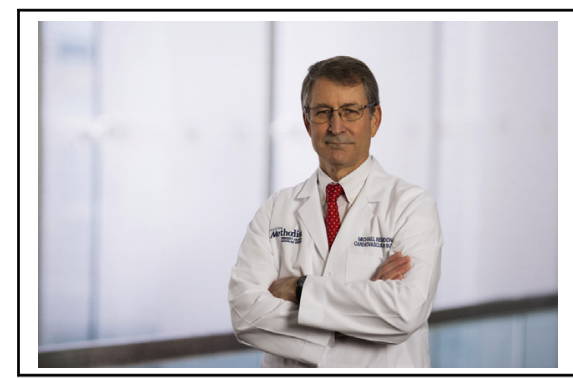

Michael J. Reardon, MD

Central Message

Imaging is central to planning the treatment for primary cardiac tumors.

See Article page 346.

malignant. Tumors of the left ventricle, particularly when apparently broad-based as this case was, raise our suspicion of malignancy because we have seen primary cardiac sarcoma arise with a similar appearance. We have found a number of useful findings on cardiac magnetic resonance imaging to help us differentiate benign from malignant

The first feature we assess is the presence of tissue plane invasion. This finding strongly favors malignancy. However, malignancy cannot be excluded by the absence of tissue invasion; therefore, we secondly assess for first-pass perfusion of the tumor. The absence of tissue invasion and absence of first-pass perfusion strongly favor a benign tumor. Last, in instances with absence of tissue invasion but evidence of first-pass perfusion, our decision tree is based on tumor size with large tumors $(>3.25 \mathrm{~cm})$ favoring malignancy, whereas smaller tumors favor benign. ${ }^{5}$ It is important to keep in mind that no single or combination of imaging findings is $100 \%$ accurate in differentiating benign from malignant, and therefore it is key to incorporate clinical judgment in the decision process. Last, we would argue that because there is a greater cost to misclassifying a malignant tumor as benign (than vice versa), it is important to maintain a high index of suspicion for malignancy when any cardiac tumor is evaluated.

For this case report, the impression that this could be resected using a transaortic valve route turned out to be correct. The tumor was completely resected, and the pathology is presented as an extremely rare mesenchymal hamartoma. Hamartomas are benign tumors composed of an overgrowth of cells normally present but often in unusual combinations and arrangements. It is difficult for us to say if the tumor is 
really a hamartoma from the pathology provided. There is no uncertainty that this is a hamartoma of a case with the usual elements of cardiac surgery present but in unusual combinations and arrangements. We congratulate Lui and co-authors on an excellent outcome and remind the reader that imaging is key in planning this success.

\section{References}

1. Liu L, Qin C, Guo Y. Rare case of left ventricular mesenchymal hamartoma. J Thorac Cardiovasc Surg. 2018;155:346-50.
2. Reardon MJ, Walkes JC, Defelice CA, Wojciechowski Z. Cardiac autotransplantation for surgical resection of a primary malignant left ventricular tumor. Tex Heart Inst J. 2006;33:495-7.

3. Walkes JC, Bavare C, Blackmon S, Reardon MJ. Transaortic resection of an apical left ventricular fibroelastoma facilitated by a thoracoscope. J Thorac Cardiovasc Surg. 2007;134:793-4.

4. Ramlawi B, Leja MJ, Abu Saleh WK, Al Jabbari O, Benjamin R, Ravi V, et al. Surgical treatment of primary cardiac sarcomas: review of a single-institution experience. Ann Thorac Surg. 2016;101:698-702.

5. M Kassi VP, Schutt RC, Nabi F, Reardon MJ, Shah D. Differentiating benign from malignant cardiac tumors with cardiac magnetic resonance imaging. J Thorac Cardiovasc Surg. 2018;155:346-50. 